\title{
Measurement of immunoglobulin concentration in cell culture supernates by computer-assisted ELISA
}

\author{
Herbert B. Slade *, Dennis E. Lopatin and Stanley A. Schwartz \\ Immunology Section, Dept. of Pediatrics, 3081 SPH-I, University of Michigan, Dental Research Institute, 1192 SE, 300 N. Ingalls St., \\ University of Michigan, and Depts. of Pediatrics, Epidemiologv and Microbiologv / Immunologv, 3073 SPH-I. University of Michigan, \\ Ann Arbor, MI 48109, U.S.A.
}

(Received 24 March 1986, accepted 27 June 1986)

The enzyme-linked immunosorbent assay (ELISA) is used extensively in immunologic research for obtaining quantitative estimates of immunoglobulin concentration in cell culture supernates. Through incorporation of a microcomputer for data acquisition, storage and rapid calculation of results, a substantial reduction in total assay time may be realized. Described here are a set of menu-driven programs written in Basic for the IBM-PC which provide advantages over existing software in simplicity, versatility and accuracy. Hardware requirements are minimal. These programs should encourage greater flexibility in terms of the size and complexity of experimental designs.

Key words: ELISA; Computer; Immunoglobulin; Cell culture

\section{Introduction}

The enzyme-linked immunosorbent assay (ELISA) has become one of the most widely used laboratory techniques for the measurement of immunogenic molecules (Engvall et al., 1971; Voller et al., 1980). In our laboratories, the ELISA is used extensively to measure isotype-specific immunoglobulin produced by lymphocytes cultured under a variety of experimental conditions. Several well documented computer-assisted techniques have been described which decrease the amount of manual effort involved in computing ELISA results, while improving the accuracy of such computations. Programs of this type were first developed for radioimmunoassays and typically involve logit transformation and/or iterative regression analysis of the sigmoidal dose-response curves (Gaines Das and Tydeman, 1980; Ventura et al., 1985).

\footnotetext{
* Address all correspondence to Dr. Slade
}

Computation of ELISA results using a similar mathematic model was described by Ritchie et al. (1981), who demonstrated a linear correlation between known and calculated concentrations of fibrinogen standards $(r=0.9957$, slope $=1.17, n$ $=10$ ) using their programs. These programs however are limited to a rigid plate design, and data entry appears to be a tedious process with the inherent risk of overloading the program if data is entered at the wrong point. The programs described by Slezak et al. (1983) utilize only the linear portion of the reaction curve to calculate reaction rates. They provide a powerful tool for screening the products of hybridomas by comparing arrays of slopes, but are not designed specifically for quantitation of immunoglobulin (Ig) concentrations in culture supernates. They too are limited by a rigid plate design.

Quantitation of isotype-specific Ig is provided by the programs described by Platt et al. (1981). These authors utilize a single sample dilution, a technique which raises serious theoretical ques- 
tions (Peterfy et al., 1983). The same drawback applies to the programs developed by Richardson et al. (1982). To avoid this shortcoming, Caulfield and Shaffer (1984) designed a program which compares endpoint titers of standards and unknowns. Although avoiding the single dilution problem, their program requires that dilution factors be determined independently prior to the assay, and allows for only three plate formats. Furthermore it is necessary to read both the standard and unknown endpoint dilutions at an optical density (OD) that is $10 \%$ of the maximal OD, thus placing constraints on dilution used and enzyme-substrate reaction time.

The programs which we describe here have been specifically designed to achieve accurate and precise results through calculations which are based only on the linear portion of the standard curve without placing stringent limitations on either assay time or plate layout. The investigator may create and store a wide variety of plate designs (templates) on the 5.25 in diskette either before or after the actual plate reading procedure. The appropriate template and stored data set may then be recalled at any time for rapid and direct calculation of results. Evaluation of the programs using serum analyzed first by rate nephelometry revealed good linear correlation for the measurement of $\operatorname{IgA}$ concentration $(r=0.9689$, slope $=$ $0.99, n=10$ ).

\section{ELISA}

The programs described are utilized for the sandwich technique of ELISA. The wells of flatbottomed polystyrene microtitration plates (NuncImmuno Plate I F, Gibco Laboratories, Lawrence, MA) are first coated for $1 \mathrm{~h}$ at $37^{\circ} \mathrm{C}$ with affinity-purified, heavy chain class-specific goat anti-human Ig (Cooper Biomedical, Malvern, PA) at a concentration of $1-5 \mu \mathrm{g} / \mathrm{ml}$ in carbonate coating buffer ( $\mathrm{pH}$ 9.6). The plates are then washed three times with phosphate-buffered saline $/ 0.05 \%$ $\mathrm{v} / \mathrm{v}$ Tween 20 (PBS-T). Appropriate dilutions of culture supernatants and affinity-purified human Ig standards (Cooper) in PBS-T are applied to the wells, and the plates are incubated in a humid chamber for $3 \mathrm{~h}$ at $25^{\circ} \mathrm{C}$. After washing the plates, alkaline phosphatase-conjugated, affinitypurified, heavy chain class-specific goat anti-human Ig (Cooper) is added at an appropriate dilution (in PBS-T) as determined by previous checkerboard analysis, and the plates are stored in a humidified chamber at $25^{\circ} \mathrm{C}$ overnight. The plates are again washed and a solution of $1.0 \mathrm{mg} / \mathrm{ml}$ of p-nitrophenyl phosphate (Sigma-104, Sigma Chemical Co., St. Louis, MO) in $1 \mathrm{M}$ diethanolamine buffer is added. The reaction is typically inhibited at $30 \mathrm{~min}$ by the addition of $1 \mathrm{~N} \mathrm{NaOH}$, although this procedure and the timing are not critical within the limits of the accuracy range of the photometer. Developed color is measured as absorbance of light at $405 \mathrm{~nm}\left(A_{405}\right)$.

\section{Hardware and specifications}

The programs are written in uncompiled Microsoft Basic for the IBM-PC microcomputer. An Apparat Ram Card (Apparat, Denver, CO) and an AST SixPakPlus (AST Research, Irvine, CA) provide a total of $640 \mathrm{~K}$ contiguous RAM. The system board switch no. 1 is set for three disk drives - two physical drives $\langle\mathrm{A}:\rangle$ and $\langle\mathrm{B}:\rangle$, and a RAM drive $\langle\mathrm{C}:\rangle$. On booting the system with the program disk in $\langle A:\rangle$, an AUTOEXEC.BAT file accesses the AST command programs to set system time and data, allocate $64 \mathrm{~K} \mathrm{RAM}$ as a print buffer, and set up drive $\langle\mathrm{C}:\rangle$ with $128 \mathrm{~K} \mathrm{RAM}$ at $\&$ H80000. BASIC.COM and all ELISA programs are then copied to $\langle\mathrm{C}:\rangle$, the menu program is loaded and execution begins. All $\mathrm{I} / \mathrm{O}$ statements anticipate a template disk in $\langle\mathrm{A}:\rangle$ and a data disk in $\langle\mathrm{B}:\rangle$. This configuration provides maximum speed and convenience for the various data manipulation tasks. The microtitration plates are read in a Titertek Multiskan photometer (Flow Laboratories, McLean, VA) and the serial binary data is transferred over a null modem cable at $2400 \mathrm{bps}$ to the AST board communications port (standard EIA RS232c (CCITTV.24) data interface) via a Multiskan Interface (Flow Laboratories). A NEC 3550 printer provides hard copy of program output. The minimum requirements for this system are an IBM-PC with a single expansion board giving $256 \mathrm{~K}$ total RAM, two physical disk drives and any parallel 8-bit printer. Not 
needed are a graphics board, graphics screen, pen plotter, or video film recorder.

\section{Computational methods and theory}

The programs are specifically designed to take advantage of the linear portion of the standard curve. The calculation program (FCALC) loads both a stored template and a stored data set into memory and, using the template as a guide, begins by identifying the $A_{405}$ values for the standards and calculating the standard curve. The theoretical basis for this operation is as follows.

The reaction of standard (Ig) with the bound coating antibody essentially follows the law of mass action, where $\operatorname{IgS}$ represents the reaction product of $I g$ with a single binding site $S$ on the coating antibody having a binding affinity constant $K_{\mathrm{A}}$ :

$K_{\mathrm{A}}=\frac{[\mathrm{IgS}]}{[\mathrm{Ig}][\mathrm{S}]}$

Substituting in terms of the total concentration of free plus bound site $[\mathrm{S}]_{\mathrm{t}}=[\mathrm{S}]+[\mathrm{IgS}]$, and using the median affinity $K_{\mathrm{o}}$ for this multivalent reaction:

$$
\begin{aligned}
& {[\mathrm{IgS}]=K_{\mathrm{o}} *[\mathrm{Ig}] *[\mathrm{~S}]} \\
& {[\mathrm{IgS}]=K_{\mathrm{o}} *[\mathrm{Ig}] *\left([\mathrm{~S}]_{\mathrm{t}}-[\mathrm{IgS}]\right)} \\
& {[\mathrm{IgS}]=\left(K_{\mathrm{o}} *[\mathrm{Ig}] *[\mathrm{~S}]_{\mathrm{t}}\right)-\left(K_{\mathrm{o}} *[\mathrm{Ig}] *[\mathrm{IgS}]\right)} \\
& 1=\frac{K_{\mathrm{o}} *[\mathrm{Ig}] *[\mathrm{~S}]_{\mathrm{t}}}{[\mathrm{IgS}]}-K_{\mathrm{o}} *[\mathrm{Ig}] \\
& {[\mathrm{IgS}]=\frac{K_{\mathrm{o}} *[\mathrm{Ig}]}{1+K_{\mathrm{o}} *[\mathrm{Ig}]} *[\mathrm{~S}]_{\mathrm{t}}}
\end{aligned}
$$

Thus, as $[\mathrm{Ig}]$ increases, $[\mathrm{IgS}]$ approaches $[\mathrm{S}]_{\mathrm{t}}$ asymptotically. This is shown graphically as the Langmuir adsorption isotherm or antigen binding capacity curve (Fig. 1). At very low total Ig, the term $[\mathrm{Ig}]$ more properly becomes $[\mathrm{Ig}]_{\mathrm{t}}-[\mathrm{IgS}]$. Because a very high proportion of Ig binds at low Ig concentrations, the curve is essentially linear near the origin (Fig. 2) while at high [Ig], there is a

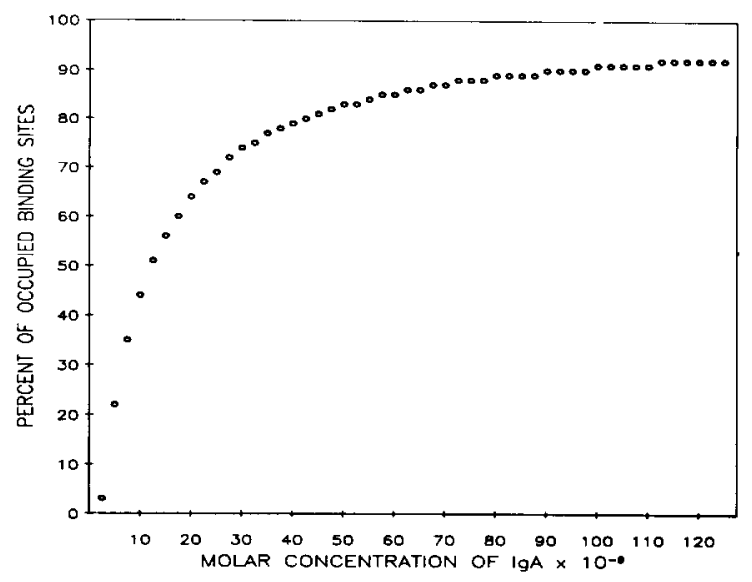

Fig. 1. Theoretical plot of percent binding as a function of free ligand (IgA) concentration (antigen binding capacity curve) over the range $5-2000 \mathrm{ng} / \mathrm{ml}$. Concentration is plotted in nmol/1. $K_{\mathrm{A}}=1 \times 10^{9} \mathrm{M}^{-1}$. This is taken as the model for the ELISA standard curves.

substantial amount of free Ig remaining in solution. Because the amount of color in each ELISA reaction well at equilibrium is directly proportional to the amount of captured Ig (Wakefield et al., 1982), $A_{405}$ may be substituted for [IgS] and the similarity between the isotherm and a typical ELISA standard curve can be seen (Figs. 3-4).

The FCALC program therefore performs linear regression analysis on the standards' $A_{405}$ values

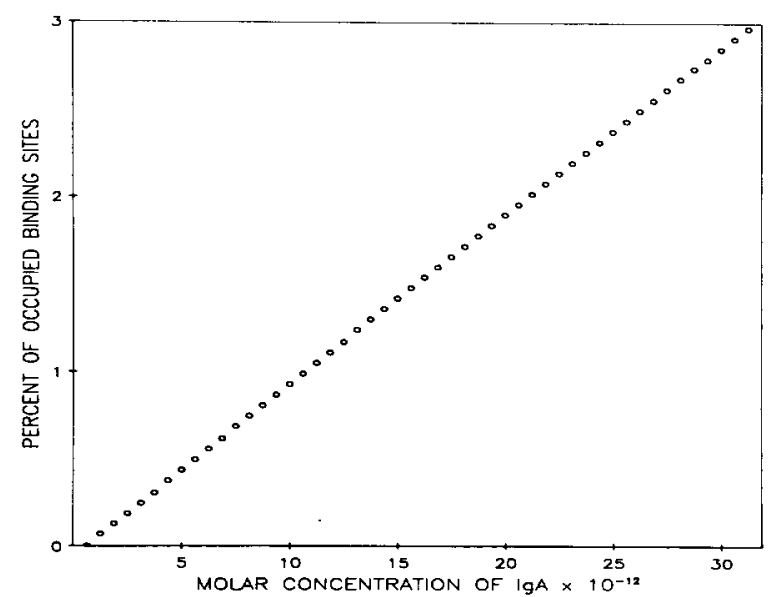

Fig. 2. Antigen-binding capacity curve for Ig concentrations in the range of $5-5000 \mathrm{pg} / \mathrm{ml}$. Concentration is plotted in pmol $/ 1$. $K_{\mathrm{A}}=1 \times 10^{9} \mathrm{M}^{-1}$. (See text for equations.) 


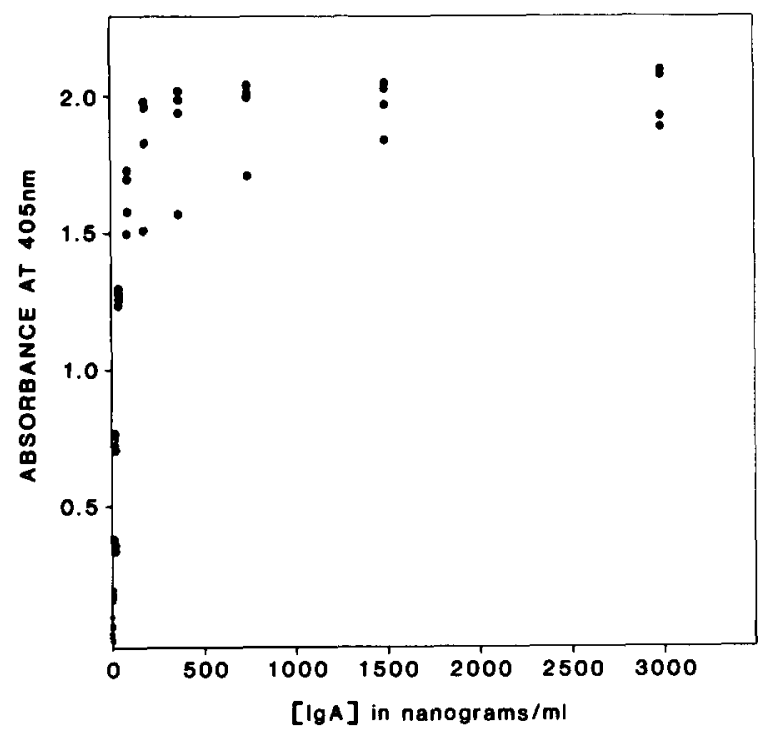

Fig. 3. Experimental ELISA results using affinity-purified human polyclonal IgA as a standard. This is the entire standard curve including the non-linear portion.

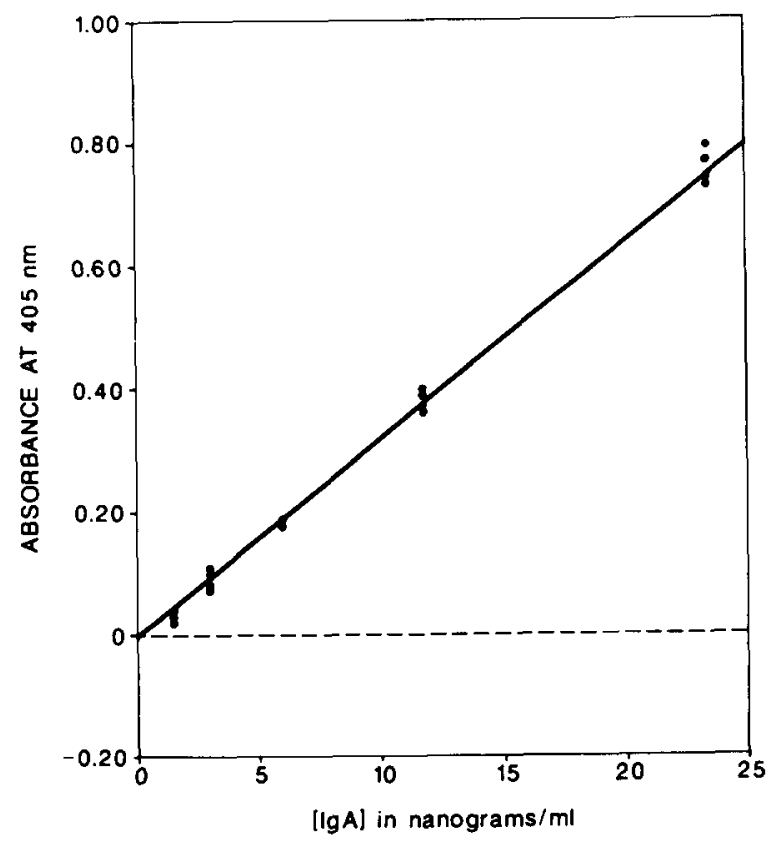

Fig. 4. Expanded view of the low concentration range, experimental standard curve. This is the portion of the curve used by the programs. Linear regression analysis yields $r=0.998$; standard error (sample) $=0.0156$. identified from the data set. Sufficient information is presented on the screen to allow the user to determine the linearity of the standard curve (Fig. 5). Significant outliers or concentrations of standard Ig which produce $A_{405}$ values beyond the linear portion of the curve are removed from analysis at this point. Plot capabilities also allow the user to visually inspect the standard curve which in our assays is entirely linear in the range of $5-120 \mathrm{ng} / \mathrm{ml}$ with reaction times $<60 \mathrm{~min}$. Regression analysis is then performed as follows for $n$ data pairs, where $x=[\mathrm{Ig}]$ and $y=A_{405}$ :

Sum $X^{2}=\operatorname{Sum} x^{2}-n \bar{x}^{2}$

Sum $X Y=\operatorname{Sum} x y-n \overline{x y}$

slope $=B=$ Sum $X Y /$ Sum $X^{2}$

$y$-intercept $=A=\bar{y}-B \bar{x}$

After calculation of the residuals, where $d=$ $Y_{\text {obs }}-Y_{\text {calc }}$ for each $x$, the standard error of the estimate is given as the square root of the Sum of $d^{2} / n$.

The experimental data actually differs somewhat from the isotherm since the law of mass action assumes a random distribution of reactants in solution, while ELISA is a two-phase system with the reaction occurring at a liquid-solid interface. In this system a retention effect occurs at low [Ig], such that the probability of a free Ig molecule forming a reaction complex with a free receptor is greater than for the corresponding reaction in solution (Delisi and Wiegel, 1981). The net flux of Ig away from the surface ( $\left.J_{-}\right)$is dependent on the number of free sites $N$ and independent of [Ig]:

$J_{-}=\frac{3 \pi * D a}{s^{2}(N s+(\pi * a))}$

However, as [Ig] becomes small compared to $[\mathrm{S}]_{t}$ the net flux of Ig toward the receptors is more dependent on [Ig] than on the number of free sites, since:

$J_{+}=4 \pi * D a[\operatorname{Ig}] \frac{N s}{N s+(\pi * a)}$

where $D$ is the diffusion constant for $\mathrm{Ig}, a$ is 
EXPERIMENT CODE: A257

Template used: A257.T1

Report Generated: 05-22-1986
EXPERIMENT DATE: 9-26-85

ASSAY DATE : 9-27-85

PERFORMED BY: HBS

IMMUNOGLOBULIN CLASS: IGA PLATE NUMBER: 1

\section{S T A N D A R D S}

\begin{tabular}{ccc}
$\begin{array}{l}\text { SEQUENCE } \\
\text { NUMBER }\end{array}$ & $\begin{array}{c}\text { STANDARD } \\
\text { CONCENTRATION }\end{array}$ & $\begin{array}{c}\text { CORRECTED } \\
\text { ADSORBANCE }\end{array}$ \\
\hline 1 & 0.0 & -0.001 \\
2 & 0.0 & -0.000 \\
3 & 0.0 & 0.005 \\
4 & 0.0 & -0.004 \\
5 & 5.0 & 0.134 \\
6 & 5.0 & 0.147 \\
7 & 5.0 & 0.155 \\
8 & 10.0 & 0.371 \\
9 & 10.0 & 0.379 \\
10 & 10.0 & 0.477 \\
11 & 15.0 & 0.491 \\
12 & 15.0 & 0.477 \\
13 & 15.0 & 1.005 \\
14 & 30.0 & 0.957 \\
15 & 30.0 &
\end{tabular}

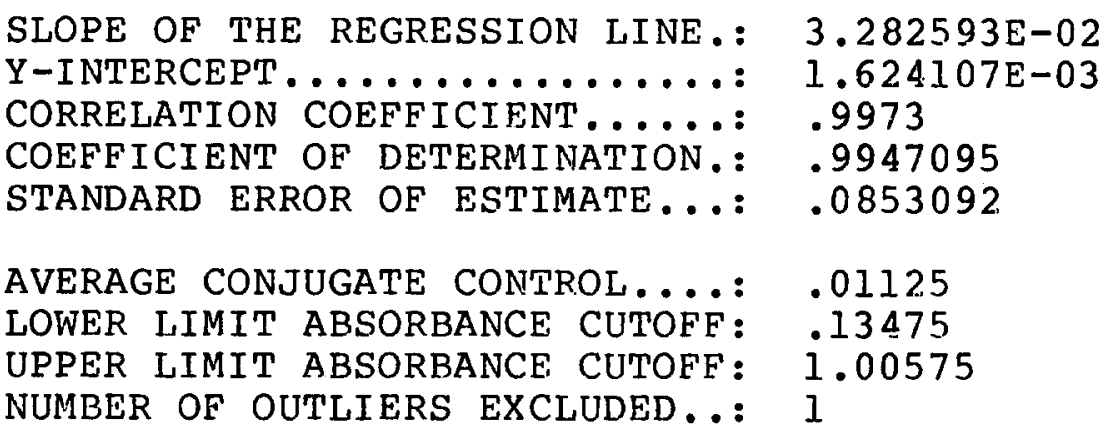

Fig. 5. Output from FCALC showing analysis of the standard curve in the sample run. This information is presented both on the screen and as a printout with the final results. If linearity cannot be appreciated from this analysis, the user may view a plot of the data on the screen.

related to the size of the solid surface, and $N$ is the number of free receptor sites of radius $s$ (Delisi, 1981).
For this reason, the slope of the regression line through standard concentration absorbance values progressively decreases to a slight degree as the 
standard concentrations decrease beyond the linear range, and thus any sample absorbance values that are less than the lower limit of the measured linear range standards will be slightly erroneous. Because these absorbance values are typically obtained at high sample dilutions $(1: 512,1: 1024$, etc.) the error becomes progressively magnified when viewed as the final calculated concentration (see Fig. 13). Therefore, the FCALC program only takes sample absorbance values which fall within the range of the linear portion of the standard curve to be accurate, and reports all other values in brackets. The limits for placing the brackets are calculated from the limits of the measured standards, with an option to assign an alternative low end cutoff. This method of utilizing only the linear portion of the standard curve has proven to be accurate and precise in multiple test runs, and avoids the more complicated computations necessary when evaluating the non-linear portions of the standard curve.

\section{Program description}

The software described is menu-driven and option-oriented, consisting of six essential programs (2028 program lines) as follows: FMENU, FDISK, FSTORE, FVIEW, FTEMP, and FCALC program. FDISK is a small utility program used to create dedicated template and data disks. Simplified program flowcharts are shown in Figs. 6-9.

Each program runs independently and can be accessed in any order. The usual sequence of program utilization begins with acquisition of data from the Multiskan plate reader using FSTORE. Unlike the programs described by Ritchie et al. (1981), FSTORE cannot be overloaded during data acquisition nor is there a risk of data loss using the described hardware configuration (Slezak et al., 1983). The user first enters the number of plates to be read and plate identifying information. Variable passing allows this information to be entered quickly even for large batch runs. Plate designations are entered as a filename (eight characters maximum) and extension (three characters) as dictated by the disk operating system. We use alphanumeric group experiment designations plus the individual plate number, giving filespecs such

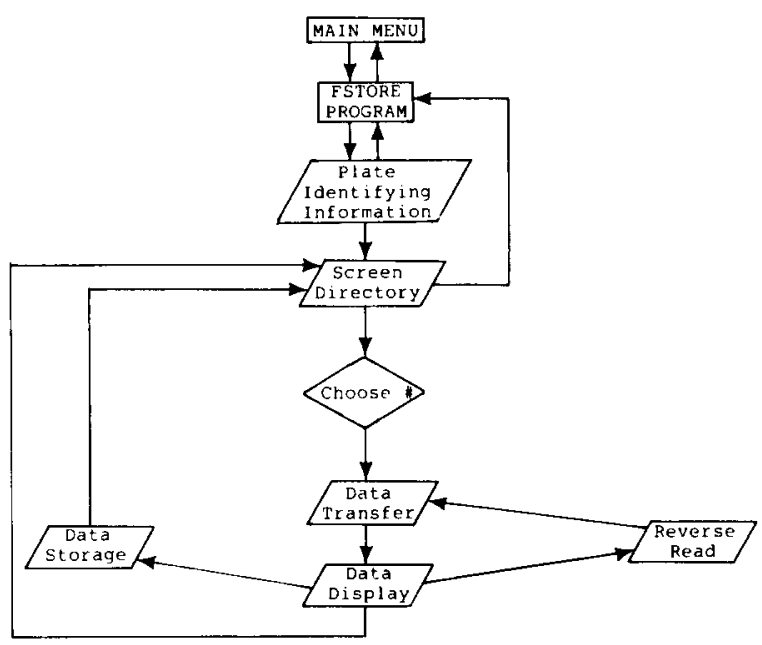

Fig. 6. Flow diagram of the data acquisition program.

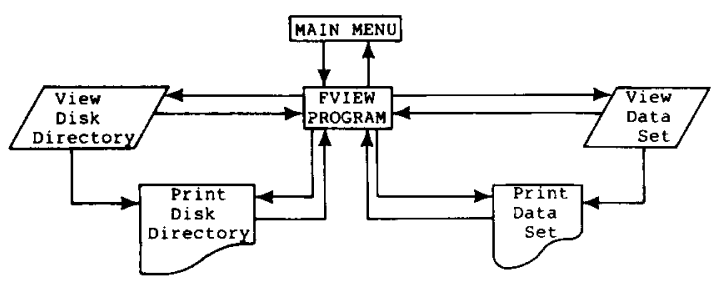

Fig. 7. Flow diagram of the data viewing program.

as 'A203.034'. Plates may be read in any order regardless of the order in which the identifying information was entered, through the use of an interactive screen directory. After reading, the absorbance data is displayed on the screen for verification.

An analysis of plate bias in our laboratory has shown that a significant error is introduced by the

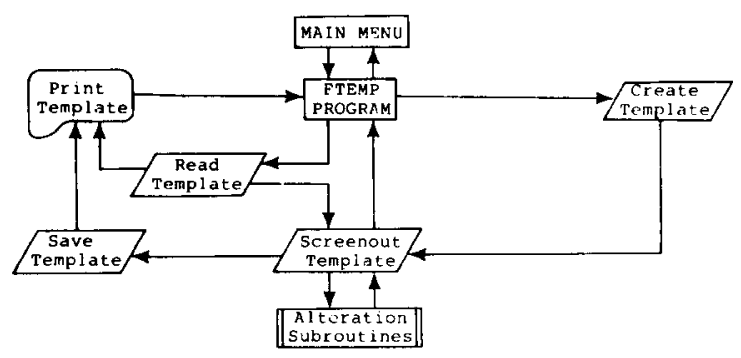

Fig. 8. Flow diagram of the template program. 


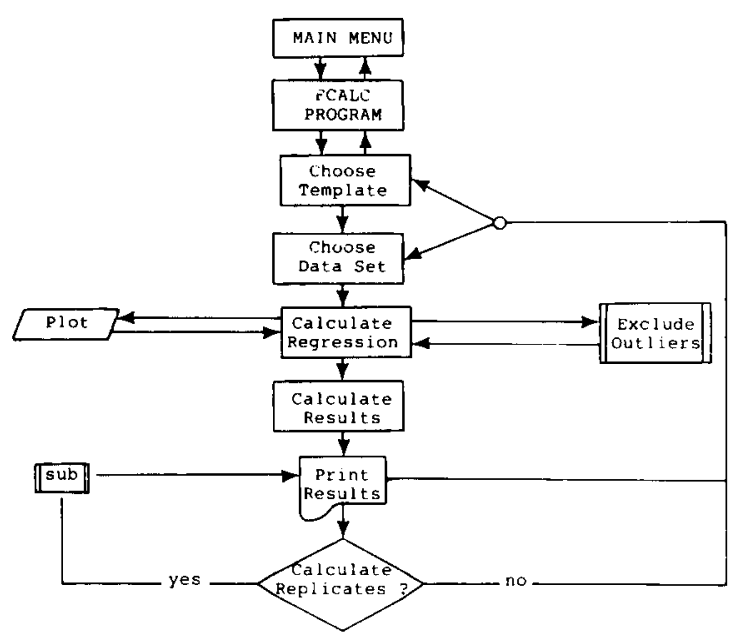

Fig. 9. Flow diagram of the calculation program.

Multiskan blanking procedure, which is performed prior to reading the plates. Because each of the eight rows on the 96-well plate is blanked against a different reference well taken from the first 8-well column, a high blank could apply to row 1 while a low blank applies to row 5, etc. The program compensates in part for this machine error by allowing the user to reverse the plate and read it again, obtaining two $A_{405}$ values for each well based on two different blanks. A Friedman two-way analysis of variance on absorbance rank order sums has shown that this blank-averaging procedure effectively reduces the error to insignificant levels (data not shown). For non-critical experiments the user may choose to store the data to disk after a single reading or dump the data and read another plate. For critical experiments requiring the highest degree of accuracy, the plate is read again in the reverse direction. When all plates have been read and the data stored, the program returns to the main menu.

The FVIEW program allows screen viewing printout of stored data sets in an $8 \times 12$ plate design including identifying information and the disk and file number (Fig. 10). This program also accesses the data disk directory, which contains the directory number, plate designation, experi-

\author{
EXPERIMENT DATE: 9-26-85 \\ ASSAY DATE: 9-27-85 \\ PERFORMED BY: HBS \\ IMMUNOGLOBULIN CLASS: IGA \\ PLATE NUMBER: 01
}

\begin{tabular}{|c|c|c|c|c|c|c|c|c|c|c|c|}
\hline $\begin{array}{l}1 \\
.003 \\
.002 \\
.003 \\
.998 \\
.008 \\
.016\end{array}$ & $\begin{array}{c}2 \\
0.010 \\
0.146 \\
0.159 \\
0.167 \\
0.489 \\
0.503 \\
0.489\end{array}$ & $\begin{array}{c}3 \\
0.011 \\
0.383 \\
0.391 \\
0.359 \\
1.017 \\
0.969 \\
1.355\end{array}$ & $\begin{array}{c}4 \\
0.006 \\
0.004 \\
0.009 \\
0.001 \\
0.005 \\
0.003 \\
0.001 \\
0.000\end{array}$ & $\begin{array}{c}5 \\
2.282 \\
2.304 \\
2.141 \\
2.094 \\
1.320 \\
1.345 \\
1.277 \\
1.316\end{array}$ & $\begin{array}{c}6 \\
2.247 \\
2.228 \\
2.176 \\
2.037 \\
0.804 \\
0.783 \\
0.744 \\
0.752\end{array}$ & $\begin{array}{c}7 \\
2.203 \\
2.230 \\
2.204 \\
1.911 \\
0.399 \\
0.415 \\
0.381 \\
0.373\end{array}$ & $\begin{array}{c}8 \\
2.190 \\
2.220 \\
2.143 \\
1.771 \\
0.197 \\
0.196 \\
0.194 \\
0.202\end{array}$ & $\begin{array}{c}9 \\
2.169 \\
2.178 \\
2.037 \\
1.710 \\
0.112 \\
0.089 \\
0.083\end{array}$ & $\begin{array}{c}10 \\
1.932 \\
1.902 \\
1.784 \\
1.538 \\
0.050 \\
0.046 \\
0.042 \\
0.051\end{array}$ & $\begin{array}{l}11 \\
0.001 \\
0.003 \\
0.002 \\
0.001 \\
0.003 \\
0.000 \\
0.001 \\
0.007\end{array}$ & $\begin{array}{r}12 \\
9.998 \\
9.998 \\
0.005 \\
0.001 \\
0.001\end{array}$ \\
\hline
\end{tabular}

Fig. 10. Sample output from FVIEW. Consistent with the convention used in the numerical output of the instrumentation (Titertek Multiskan), this program displays negative absorbance values as (value +10 ). Since no $\log$ transformations are employed in the calculations, actual positive, zero, and negative absorbance data are used in all calculations and printouts of calculated results. 
ment date, assay date, operator's initials, and Ig class for each of 110 stored data sets per double sided diskette.
Prior to calculating the results, the experimental plate design must be stored as a template using the FTEMP program. In addition to allowing the

\begin{tabular}{|c|c|c|c|c|c|c|c|c|c|c|c|c|}
\hline & 1 & 2 & 3 & 4 & 5 & 6 & 7 & 8 & 9 & 10 & 11 & 12 \\
\hline A & $-\cdots$ & 0 & 0 & --- & $\begin{array}{c}-1- \\
1\end{array}$ & $\begin{array}{c}-5- \\
2\end{array}$ & $\begin{array}{c}-9- \\
4\end{array}$ & $\begin{array}{c}-13- \\
8\end{array}$ & $\begin{array}{r}-17- \\
16\end{array}$ & $\begin{array}{r}-21- \\
32\end{array}$ & -- & ---- \\
\hline B & -- & 5 & 10 & --- & $\begin{array}{c}-2- \\
1\end{array}$ & $\begin{array}{c}-6- \\
2\end{array}$ & $\begin{array}{c}-10- \\
4\end{array}$ & $\begin{array}{c}-14- \\
8\end{array}$ & $\begin{array}{r}-18- \\
16\end{array}$ & $\begin{array}{r}-22- \\
32\end{array}$ & $-\infty$ & - \\
\hline C & --- & 5 & 10 & --- & $\begin{array}{c}-3- \\
1\end{array}$ & $\begin{array}{c}-7- \\
2\end{array}$ & $\begin{array}{c}-11- \\
4\end{array}$ & $\begin{array}{c}-15- \\
8\end{array}$ & $\begin{array}{r}-19- \\
16\end{array}$ & $\begin{array}{r}-23- \\
32\end{array}$ & -- & - \\
\hline D & -- & 5 & 10 & $\cdots$ & $\begin{array}{c}-4- \\
1\end{array}$ & $\begin{array}{c}-8- \\
2\end{array}$ & $\begin{array}{c}-12- \\
4\end{array}$ & $\begin{array}{c}-16- \\
8\end{array}$ & $\begin{array}{r}-20- \\
16\end{array}$ & $\begin{array}{r}-24- \\
32\end{array}$ & $-\cdots$ & \\
\hline$E$ & --- & 15 & 30 & $-\cdots$ & $\begin{array}{r}-25- \\
64\end{array}$ & $\begin{array}{r}-29- \\
128\end{array}$ & $\begin{array}{r}-33- \\
256\end{array}$ & $\begin{array}{r}-37- \\
512\end{array}$ & $\begin{array}{r}-41- \\
1024\end{array}$ & $\begin{array}{r}-45- \\
2048\end{array}$ & -- & \\
\hline F & ---- & 15 & 30 & $-\cdots$ & $\begin{array}{r}-26- \\
64\end{array}$ & $\begin{array}{r}-30- \\
128\end{array}$ & $\begin{array}{r}-34- \\
256\end{array}$ & $\begin{array}{r}-38- \\
512\end{array}$ & $\begin{array}{r}-42- \\
1024\end{array}$ & $\begin{array}{l}-46- \\
2048\end{array}$ & - & \\
\hline G & ---- & 15 & 30 & ---- & $\begin{array}{r}-27- \\
64\end{array}$ & $\begin{array}{r}-31- \\
128\end{array}$ & $\begin{array}{r}-35- \\
256\end{array}$ & $-39-$ & $\begin{array}{r}-43- \\
1024\end{array}$ & $\begin{array}{l}-47- \\
2048\end{array}$ & -- & - \\
\hline$M$ & --- & 0 & 0 & --- & $\begin{array}{r}-28- \\
64\end{array}$ & $\begin{array}{r}-32- \\
128\end{array}$ & $\begin{array}{r}-36- \\
256\end{array}$ & $\begin{array}{r}-40- \\
512\end{array}$ & $\begin{array}{r}-44- \\
1024\end{array}$ & $\begin{array}{r}-48- \\
2048\end{array}$ & -ー- & \\
\hline
\end{tabular}

NOTE:

Zero's are conjugate controls

---- represents empty wells

Numbers from 1 to 48 show the secruence for data analys is

Below sequence values are the dilution factors

Fig. 11. Output from FTEMP showing the template used in the example run. The triplicate values from 5 to 30 represent concentrations of standards in $\mathrm{ng} / \mathrm{ml}$. This is only one of multiple designs which are routinely used. 
EXPERIMENT DATE: 9-26-85

ASSAY DATE : $9-27-85$

PERFORMED BY: HBS

IMMUNOGLOBULIN CLASS: IGA

PLATE NUMBER: 1

S A H P L E S

\begin{tabular}{|c|c|c|c|c|}
\hline $\begin{array}{l}\text { SEQUENCE } \\
\text { NUMBER }\end{array}$ & $\begin{array}{l}\text { CORRECTED } \\
\text { ABSORBANCE }\end{array}$ & $\begin{array}{l}\text { CALCULATED } \\
\text { CONCENTRATION }\end{array}$ & $\begin{array}{l}\text { DILUTION } \\
\text { FACTOR }\end{array}$ & $\begin{array}{c}\text { FINAL } \\
\text { CONCENTRATION }\end{array}$ \\
\hline $\begin{array}{l}1 \\
2 \\
3 \\
4 \\
5 \\
6 \\
7 \\
8 \\
9 \\
10 \\
11 \\
12 \\
13 \\
14 \\
15 \\
16 \\
17 \\
18 \\
19 \\
20 \\
21 \\
22 \\
23 \\
24 \\
25 \\
26 \\
27 \\
28 \\
29 \\
30 \\
31 \\
32 \\
33 \\
34 \\
35 \\
36 \\
37 \\
38 \\
39 \\
40 \\
41 \\
42 \\
43 \\
44 \\
45 \\
46 \\
47 \\
48\end{array}$ & $\begin{array}{l}{[2.270]} \\
{[2.292]} \\
{[2.129]} \\
{[2.082]} \\
{[2.235]} \\
{[2.216]} \\
{[2.164]} \\
{[2.025]} \\
{[2.191]} \\
{[2.218]} \\
{[2.192]} \\
{[1.899]} \\
{[2.178]} \\
{[2.208]} \\
{[2.131]} \\
{[1.759]} \\
{[2.157]} \\
{[2.166]} \\
{[2.025]} \\
{[1.698]} \\
{[1.920]} \\
{[1.890]} \\
{[1.772]} \\
{[1.526]} \\
{[1.308]} \\
{[1.333]} \\
{[1.265]} \\
{[1.304]} \\
0.792 \\
0.771 \\
0.732 \\
0.740 \\
0.387 \\
0.403 \\
0.369 \\
0.361 \\
0.185 \\
0.184 \\
0.182 \\
0.190 \\
{[0.100]} \\
{[0.077]} \\
{[0.071]} \\
{[0.113]} \\
{[0.038]} \\
{[0.034]} \\
{[0.030]} \\
{[0.039]}\end{array}$ & $\begin{array}{r}69.1 \\
69.7 \\
64.8 \\
63.3 \\
68.0 \\
67.4 \\
65.8 \\
61.6 \\
66.7 \\
67.5 \\
66.7 \\
57.8 \\
66.3 \\
67.2 \\
64.8 \\
53.5 \\
65.6 \\
65.9 \\
61.6 \\
51.7 \\
58.4 \\
57.5 \\
53.9 \\
46.4 \\
39.8 \\
40.5 \\
38.5 \\
39.6 \\
24.1 \\
23.4 \\
22.2 \\
22.5 \\
11.7 \\
12.2 \\
11.2 \\
10.9 \\
5.6 \\
5.5 \\
5.5 \\
5.7 \\
3.0 \\
2.3 \\
2.1 \\
3.4 \\
1.1 \\
1.0 \\
0.8 \\
1.1\end{array}$ & $\begin{array}{r}1.0 \\
1.0 \\
1.0 \\
1.0 \\
2.0 \\
2.0 \\
2.0 \\
2.0 \\
4.0 \\
4.0 \\
4.0 \\
4.0 \\
8.0 \\
8.0 \\
8.0 \\
8.0 \\
16.0 \\
16.0 \\
16.0 \\
16.0 \\
32.0 \\
32.0 \\
32.0 \\
32.0 \\
64.0 \\
64.0 \\
64.0 \\
64.0 \\
128.0 \\
128.0 \\
128.0 \\
128.0 \\
256.0 \\
256.0 \\
256.0 \\
256.0 \\
512.0 \\
512.0 \\
512.0 \\
512.0 \\
1024.0 \\
1024.0 \\
1024.0 \\
1024.0 \\
2048.0 \\
2048.0 \\
2048.0 \\
2048.0\end{array}$ & $\begin{array}{r}69.1 \\
69.7 \\
64.8 \\
63.3 \\
136.1 \\
134.9 \\
131.7 \\
123.3 \\
266.8 \\
270.1 \\
266.9 \\
231.2 \\
530.5 \\
537.8 \\
519.1 \\
428.4 \\
1050.9 \\
1055.3 \\
986.5 \\
827.2 \\
1870.8 \\
1841.5 \\
1726.5 \\
1486.7 \\
2548.4 \\
2597.2 \\
2464.6 \\
2540.6 \\
3084.8 \\
3002.9 \\
2850.9 \\
2882.1 \\
3011.2 \\
3136.0 \\
2870.9 \\
2808.5 \\
2871.8 \\
2856.2 \\
2825.0 \\
2949.8 \\
3092.2 \\
2374.7 \\
2187.5 \\
3497.7 \\
2316.2 \\
2066.7 \\
1817.1 \\
2378.6\end{array}$ \\
\hline
\end{tabular}

Fig. 12. Output from FCALC showing concentrations calculated from the absorbance values. Values in brackets are outside the range of the measured standard curve and will yield inaccurate results. The peak concentrations are seen in the range of the standard curve. The final analysis is seen in Fig. 13. 
user to create a new template, this program allows alteration, viewing, or printing of previously stored templates. During template creation and alteration, information is input from the keyboard as individual or more rapidly as grouped row $/ \mathrm{col}-$ umn coordinates. The screen displays the task in progress, the values last entered, the status of the NumLock and CapsLock keys, and any special instructions. The sequence of coordinate assignments for the samples determines the sequence of analysis during the calculation program. Therefore plate assignments of replicate sample dilutions must be input consecutively, but no limitation is placed on their actual location on the plate relative to each other. Unassigned coordinates default to blanks and results are not calculated from the corresponding absorbance readings in the stored data set. Any coordinate in the $8 \times 12$ array may be designated to contain a conjugate control ([Ig] $=0$ ), a standard concentration $([\mathrm{Ig}]>0)$, or a sample $([\mathrm{Ig}]=$ unknown, dilution factor entered $)$.

EXPERIMENT CODE: A257

R E P L I C A T
The program traps all common errors, thus avoiding time consuming restarts. A highlighted screen display allows the user to view the newly created template prior to storage in the event that alteration is desired. After storage, a printout of the template is automatically generated (Fig. 11).

The calculation program, FCALC, first accesses and displays the template disk directory. The user may scan multiple diskettes prior to choosing the appropriate template. The chosen template is then loaded into memory and the desired data set is similarly retrieved. The program uses the template to identify conjugate controls and standards. The average absorbance value of the conjugate controls is calculated and subtracted from all $96 A_{405}$ values. Linear regression analysis is then performed on the controls plus standards. Outliers may be excluded and the regression line recalculated (the average conjugate control is first recomputed if conjugate control outliers were excluded). The original data set may be recovered from mem-

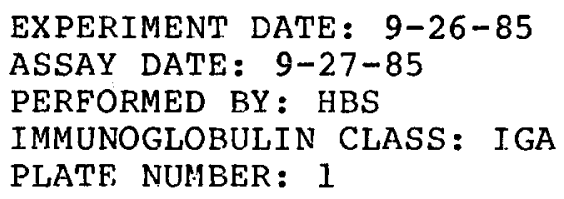


ory at any time. After satisfactorily defining the linear regression line for the standards with the aid of on-screen statistical data and plots, the sample results are automatically calculated by comparing each sample $A_{405}$ value to the standard curve. The results of sample replicate-wells averages are then computed and printed along with standard deviation and standard error values. The $64 \mathrm{~K}$ print buffer allows the user to calculate the next data set while previous results are being printed. A single plate can be completely calculated within $4 \mathrm{~min}$ of obtaining the raw data from the Multiskan. FCALC allows recall of directories and exchanging of templates for rapid sequential calculation of multiple stored data sets.

\section{Example of program runs}

A known concentration of human polyclonal IgA was used as the sample. The plate (see Fig. 11) represents one of many possible layouts, here designed to maximize accuracy through avoidance of columns 1 and 12 which have been found in our lab to yield spuriously low absorbance values. Quadruplicates of each dilution are not necessary for accuracy, and more typically we utilize four duplicate dilutions (serial or otherwise) per sample yielding eight samples per plate. The actual data from the sample run is shown in Fig. 9, produced using FVIEW. The absorbance values reported by FCALC (Fig. 12) have been corrected by subtracting the average of conjugate control absorbances. As noted above, the calculated results may be inaccurate at either extreme of the dilution series. The final result is therefore taken as the peak calculated value, or the average of peaks where a plateau occurs, using only those values calculated from non-bracketted absorbances (Fig. 13). This technique satisfies the desirability of testing multiple dilutions without imposing the constraint of identifying an endpoint dilution.

\section{Availability}

Complete program listings are available from the authors upon request.

\section{Acknowledgements}

These studies were aided by National Institutes of Health Grants numbers 1-RO1-CA35922 and 1-RO1-AI19890. Dr. Schwartz is a recipient of a Research Career Development Award from the National Cancer Institute (no. 1-KO4-CA00896).

The authors wish to thank Dr. Morton B. Brown for his invaluable assistance with the statistical analyses.

\section{References}

Caulfield, M.J. and D. Shaffer, 1984, J. Immunol. Methods 74, 205.

DeLisi, C., 1981, Mol. Immunol. 18, 507.

DeLisi, C. and F.W. Wiegel, 1981, Proc. Natl. Acad. Sci. U.S.A. 78, 5569.

Engvall, E., G. Jonsson and P. Perlmann, 1971, Biochim. Biophys. Acta 251, 247.

Gaines Das, R.E. and M.S. Tydeman, 1980, Comput. Programs. Biomed. 15, 13.

Platt, J.H., A.B. Shore, A.M. Smithyman and G.L. Kampfner, 1981, J. Immunoassay 2, 59.

Richardson, M.D., A. Turner, D.W. Warnock and P.A. Llewellyn, 1983, J. Immunol. Methods 56, 201.

Ritchie, D.G., J.M. Nickerson and G.M. Fuller, 1981, Anal. Biochem. 110, 281.

Slezak, T.R., M. Vanderlaan and R.H. Jensen, 1983 J. Immunol. Methods 65, 83.

Ventura, M., R. Mollicone and N. Thobie, 1985, J. Immunol. Methods 78, 1 .

Voller, A., D. Bidwell and A. Bartlett, 1980, in: Manual of Clinical Immunology, eds. N.R. Rose and H. Friedman (American Society for Microbiology, Washington, DC) pp. 359-371.

Wakefield, E.F., M.J. Shelton and C.S. Hosking, 1982, Clin. Chim. Acta 123, 303. 